\title{
New approach to the calculation of pistachio powder hysteresis
}

\author{
Hamid Tavakolipour ${ }^{1}$ and Mohsen Mokhtarian ${ }^{2 *}$ \\ ${ }^{1}$ Department of Food Science and Technology, Sabzevar Branch, Islamic Azad University, Sabzevar, Iran \\ ${ }^{2}$ Young Researchers and Elite Club, Sabzevar Branch, Islamic Azad University, Sabzevar, Iran \\ Received November 18, 2015; accepted April 20, 2016
}

\begin{abstract}
A b s t r a c t. Moisture sorption isotherms for pistachio powder were determined by gravimetric method at temperatures of 15 , 25,35 and $40^{\circ} \mathrm{C}$. A selected mathematical models were tested to determine the best suitable model to predict isotherm curve. The results show that Caurie model had the most satisfactory goodness of fit. Also, another purpose of this research was to introduce a new methodology to determine the amount of hysteresis at different temperatures by using best predictive model of isotherm curve based on definite integration method. The results demonstrated that maximum hysteresis is related to the multi-layer water (in the range of water activity 0.2-0.6) which corresponds to the capillary condensation region and this phenomenon decreases with increasing temperature.
\end{abstract}

$\mathrm{K}$ e y w o r d s: hysteresis, pistachio powder, sorption isotherm, storage

\section{INTRODUCTION}

Pistachio (Pistacia vera L.) a plant from the Anacardiaceae family (Saitta et al., 2009), is one of the most important Persian horticultural products with high export value. Various varieties of this nut have different tastes and flavours, and its annual production in 2012 in three major producing countries (Iran, U.S.A and Turkey) was close to 472000,231000 and 150000 metric tons, respectively (Arena et al., 2013; FAO 2012). As regards Iran, a major part of the country pistachio production as non-oil products is exported, so - economically - this crop is an important source providing foreign currency income. Thus, in view of the important position of this product in the economy, knowledge of the suitable preservation and storage conditions is important to prevent spoilage and damage.

\footnotetext{
*Corresponding author e-mail: mokhtarian.mo@gmail.com
}

Water activity is one of the most important parameters during various postharvest operations such as drying, storage and packaging, as it is related to the amount of water available in the food material for physical, chemical and biochemical reactions (such as lipid oxidation and browning reactions), as well as for microbiological growth (Tavakolipour, 2015; Tavakolipour and Kalbasi Ashtari, 2008). Sorption isotherms can be generated from an adsorption process (starting from a dry system having a zero water activity) or a desorption process (starting with a wet system having a water activity value of 1 ). The difference between these curves is defined as hysteresis. Desorption isotherms usually give higher moisture content than adsorption isotherms. The composition of the product, its temperature, storage time, drying temperature, and the number of successive adsorption and desorption cycles affect hysteresis (Sahin and Sumnu, 2006). Various studies have been done in this field for different products. Muzaffar and Kumar (2016) investigated the moisture sorption isotherm of spray dried tamarind pulp powder. The results indicated that the Guggenheim, Anderson and De Boer (GAB), followed by the Oswin model, best fitted the experimental data. Sadeghi et al. (2016) evaluated the moisture sorption isotherm and the glass transition temperature of date powder in terms of various model systems. They reported that the GAB model predicted experimental data more accurately. Majd et al. (2014) studied the thermodynamic properties of water sorption isotherms of grape seed. Those researchers claim that the Ferro-Fontan and Peleg models, due to greater $\mathrm{R}^{2}$ values (or lowest standard error), were chosen as a best fitted models to predict experimental data. Ocieczek (2014)

(C) 2016 Institute of Agrophysics, Polish Academy of Sciences 
evaluated the sorption properties of milk powder with lactose (ML) and without lactose (MB). The results show that the sorption curves for ML and MB powdered milk samples were categorised as type II isotherm according to the classification by Brunauer and co-workers. Also, that researcher affirmed that lactose-free milk had sorption properties that determined better storage stability in comparison with lactose-containing powdered milk. Staudt et al. (2013) used a new method for predicting sorption isotherms at different temperatures, using the Brunauer-Emmett-Teller (BET) model. The new approach was tested with different food materials and the predicted results were in good agreement with experimental data, attesting the potential of this new approach. In another study, Zomorodian et al. (2011) used thirteen available mathematical models to find the best fit isotherm curve model for canola seed. The result demonstrated that the Halsey model had the best correlation to predict isotherm curve. Moreira et al. (2009) developed a simplified algorithm for predicting the water sorption isotherms of some foods based upon chemical composition. Zomorodian and Tavakoli (2007) studied the adsorption and desorption equilibrium moisture content of two major varieties of Iranian pistachios (Ohadi and Kalehghochi) at 11 to $85 \%$ relative humidity and a constant temperature of $50^{\circ} \mathrm{C}$. They claimed that the Halsey model is the most proper equation for the adsorption process for the two varieties, whereas the Oswin and Smith models were the most appropriate for the desorption process at $50^{\circ} \mathrm{C}$.

The main aim of this study was to present the new methodology for the calculation of the hysteresis loop area for pistachio powder and to determine the best predictive model for the estimation of its isotherm curve.

\section{MATERIAL AND METHODS}

Raw and dried Kerman variety whole pistachios were purchased from a local market. The pistachio nuts should be dried from a moisture content of about $40 \%$ to a safe storage moisture of less than 7\% wet basis (w.b.). Pistachio nuts dried to a range of 4-6\% (w.b.) are graded higher in sensory quality indicators such as crispness and sweetness, and lower in bitterness and rancidity than those dried in the range of $6-11 \%$ (w.b.) moisture content. Pistachio powder was produced by weighing $10 \mathrm{~g}$ of pistachio kernels crushed in a home mill (Black and Decker, London, U.K.) for $30 \mathrm{~s}$ until its average particle size reached 250 microns. Various saturated salt solutions including $\mathrm{LiCl}, \mathrm{CH}_{3} \mathrm{COOK}$, $\mathrm{MgCl}_{2}, \mathrm{~K}_{2} \mathrm{CO}_{3}, \mathrm{Mg}\left(\mathrm{NO}_{3}\right)_{2}, \mathrm{NaNO}_{2}, \mathrm{NaCl}$ and $\mathrm{KCl}$ were used to obtain constant relative humidity (Tavakolipour and Kalbasi Ashtari, 2008).

In the first stage, various precise measurement devices such as micrometers and calipers were used to determine the length, width and thickness of pistachio nuts and kernels. Because the main object of this research was focused on pistachio powder, sorption isotherms of pistachio powder were determined by a static gravimetric method at 15 ,
25, 35 and $40^{\circ} \mathrm{C}$. According to Tavakolipour and Kalbasi Ashtari (2008), eight saturated salt solutions were prepared to provide $0.11,0.23,0.36,0.49,0.62,0.75$ and $0.88 a_{w}$ (water activity) values. After transferring $150 \mathrm{ml}$ of each salt solution into separate glass jars, the jar grids were suspended. About $2 \mathrm{~g}$ samples of pistachio powder were weighed separately and placed on grids in the jars, which were then tightly closed and kept in convective ovens at different temperatures for equilibration. The time required to reach equilibrium moisture content for the pistachio powder samples was close to 18 days. Equilibration was achieved when the changes in moisture content (d.b.) did not exceed $0.1 \%$, and it was less than $0.001 \mathrm{~g} \mathrm{~g}^{-1}$ dry solids for three consecutive weighings at 3-day intervals (Biquet and Labuza, 1988). A vacuum oven at $70^{\circ} \mathrm{C}$ and $150 \mathrm{mbar}$ was used for $6 \mathrm{~h}$ to measure the moisture content of each pistachio sample (AOAC, 1990).

Following equation was used to calculated moisture content:

$$
M C_{d . b .}=\frac{M_{w}}{M_{i}-M_{w}}=\frac{M_{w}}{M_{s}},
$$

where: $M C_{d . b .}$ is moisture content in dry basis, $M_{w}$ is the weight of evaporated water $(\mathrm{g}), M_{i}$ is the initial mass of sample (g) and $M_{s}$ is the weight of dry matter (g).

For the adsorption process, pistachio samples were placed in suspended dishes in jars containing silica gel. Again, the same procedure was repeated to reach the equilibrium moisture content. Desorption isotherms were determined on samples hydrated in a glass jar over distilled water. At high $a_{w}$ values $\left(a_{w}>0.7\right)$, a small amount of toluene was placed in a capillary tube fixed to the inner wall of different jars to prevent microbial spoilage of the pistachio samples (Labuza, 1984).

To determine the best model in fitting of moisture sorption isotherm data of pistachio powder at different temperatures, six selected equilibrium moisture content (EMC) mathematical models were used. These models included BET, GAB, Iglesias and Chirife, Freundlich, Halsey and Caurie (Noshad et al., 2012; Shivhare et al., 2004). The equations of these models are presented in Table 1.

T a b l e 1. Selected EMC mathematical models for the fitting of sorption data of pistachio powder

\begin{tabular}{ll}
\hline Models & Equation \\
\hline BET & $\mathrm{X}=\mathrm{X}_{\mathrm{o}} \mathrm{C} a_{w} /\left[\left(1-a_{w}\right)\left(1-a_{w}+\mathrm{C} a_{w}\right)\right]$ \\
GAB & $\mathrm{X}=\mathrm{X}_{\mathrm{o}} \mathrm{CK} a_{w} /\left[\left(1-\mathrm{K} a_{w}\right)\left(1-\mathrm{K} a_{w}+\mathrm{CK} a_{w}\right)\right]$ \\
Iglesias and Chirife & $\mathrm{X}=\mathrm{A}+\mathrm{B}\left[a_{w} /\left(1-a_{w}\right)\right]$ \\
Freundlich & $\mathrm{X}=\mathrm{A}\left(a_{w}\right)^{1 / \mathrm{B}}$ \\
Halsey & $\mathrm{X}=\left[-\mathrm{K} / \ln \left(a_{w}\right)\right]^{1 / \mathrm{n}}$ \\
Caurie & $\mathrm{X}=\exp \left(\mathrm{A}+\mathrm{B} a_{w}\right)$ \\
\hline
\end{tabular}


Two statistical criteria, $i e$ the coefficient of determination $\left(\mathrm{R}^{2}\right)$ and root mean relative error (MRE), were used to evaluate the agreement of the experimental data with the different models (Mokhtarian et al., 2014). Each model with the highest $\mathrm{R}^{2}$ value and the lowest MRE value is the best model for fitting of sorption moisture isotherm data of pistachio powder (Tavakolipour and Mokhtarian, 2012). Also, it is necessary to note that data fitting was carried out by Sigma Plot (version 11, London, UK) software version.

The Statistical program (Statistix software, version 8, USA) was used to perform ANOVA (analysis of variances) for the recorded data (obtained from the two replicates of each treatments) and to compare the mean values by using the least significant difference (LSD) test at a confidence level of $95 \%$.

a

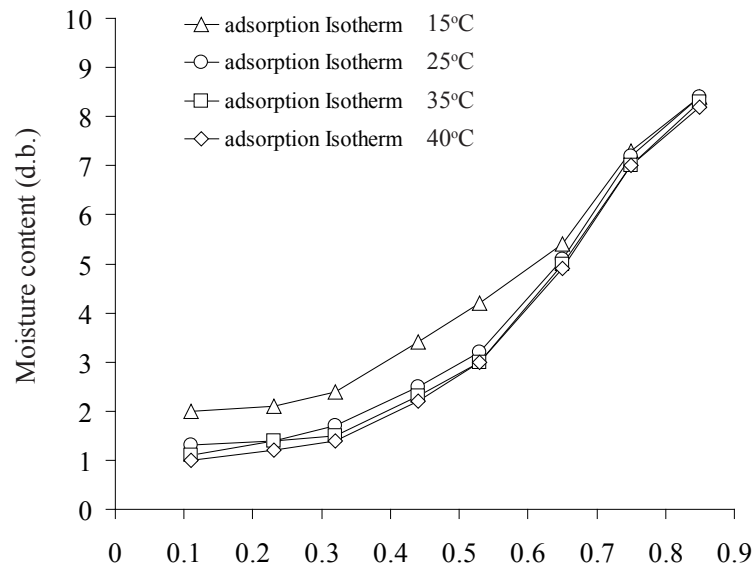

b

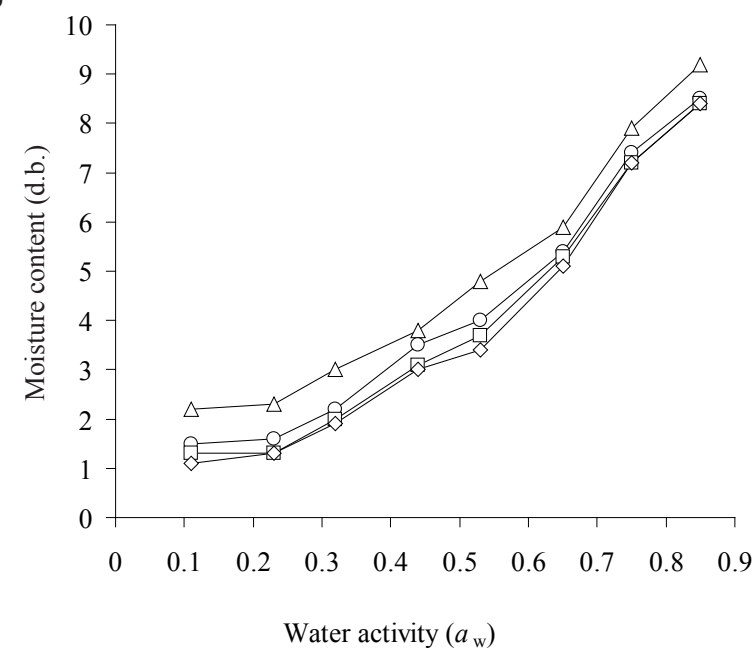

Fig 1. Effects of different storage temperatures on the sorption curves of pistachio powder: $\mathrm{a}$ - adsorption, $\mathrm{b}$ - desorption.

\section{RESULTS AND DISCUSSION}

The adsorption/desorption isotherms for pistachio powder at $15,25,35$, and $40^{\circ} \mathrm{C}$ are shown in Fig. 1. The equilibrium moisture content at each water activity represents the mean value of two replications. At a constant temperature, the equilibrium moisture content (adsorption/desorption) of pistachio powder increases considerably with rising $a_{w}$. This behaviour is manifested in the form of a sigmoid shape curve, thus reflecting a Type II isotherm according to the BET classification (Brunauer et al., 1938; Ocieczek, 2012). Singh et al. (2001) stated that the isotherm curve of smoked chicken sausages complied with Type II isotherm, which is more congruent with the output of this study.

Also, Fig. 1 clearly indicates that, at constant $a_{w}$, the moisture content of the samples decreased with increasing temperature from 15 to $40^{\circ} \mathrm{C}$. At increased temperatures, the attractive forces between molecules decrease due to an increase in the kinetic energy of water molecules. This leads to the increase of their mobility. Therefore, water molecules with slow motion at low temperatures are bound more easily to suitable binding sites on surface (Mrad et al., 2013). Similar results were observed by Polatoğlu et al. (2011) and Noshad et al. (2012) regarding sucuk and quince, respectively. However, some sugars and low molecular weight food components are exceptions, and with increasing temperature they will become more hygroscopic (Ayrancy and Dalgic, 1992).

The ANOVA results for the interaction effects of water activity and storage temperature on both adsorption and desorption moisture content of pistachio powder is shown in Table 2. The results illustrated that water activity and storage temperatures had a significant effect $(p<0.05)$ on the EMC of pistachio power. In terms of adsorption moisture content, the greatest EMC was observed at $a_{w}=0.85$ and storage temperature of $15^{\circ} \mathrm{C}$ (or $25^{\circ} \mathrm{C}$ ), and with increasing storage temperature (at constant $a_{w}$ ) it was reduced. Also, the lowest EMC was observed at $a_{w}=0.11$ and storage temperature of $40^{\circ} \mathrm{C}$. In addition, a similar trend was reported regarding to desorption moisture content of pistachio powder (Table 2).

To introduce a suitable model for describing the equilibrium behaviour of pistachio powder and providing good fitting of experimental adsorption and desorption EMC data, various mathematical models, namely, Brunauer-EmmettTeller (BET), Guggenheim, Anderson and de Boer (GAB), Iglesias and Chirife, Freundlich, Halsey and Caurie were used. The values of these parameters, together with model constants at various temperatures, are listed in Table 3. Two statistical parameters, ie $\mathrm{R}^{2}$ and MRE, were used to evaluate these models. The results show that $\mathrm{R}^{2}$ and MRE ranged between $0.550-0.990$ and 4.420 to 27.35 , respectively. Also, the Caurie model had better fit than the other models to explain the adsorption and desorption EMC of 
T a b l e 2. ANOVA results of the interaction effects of $\left(a_{w} \times\right.$ temp. $)$ on the EMC (adsorption and desorption) of pistachio powder

\begin{tabular}{|c|c|c|c|c|}
\hline \multirow{2}{*}{$\begin{array}{c}\text { Water } \\
\text { activity }\end{array}$} & \multicolumn{4}{|c|}{ Storage temperature $\left({ }^{\circ} \mathrm{C}\right)$} \\
\hline & 15 & 25 & 35 & 40 \\
\hline \multicolumn{5}{|c|}{ adsorption } \\
\hline 0.11 & $2.02 \mathrm{t}$ & $1.30 \mathrm{x}$ & $1.10 \mathrm{yz}$ & $1.00 \mathrm{z}$ \\
\hline 0.23 & $2.10 \mathrm{~s}$ & $1.40 \mathrm{w}$ & $1.40 \mathrm{w}$ & $1.20 \mathrm{y}$ \\
\hline 0.32 & $2.40 \mathrm{p}$ & $1.70 \mathrm{u}$ & $1.50 \mathrm{v}$ & $1.40 \mathrm{w}$ \\
\hline 0.44 & 3.401 & $2.50 \mathrm{o}$ & $2.30 \mathrm{q}$ & $2.20 \mathrm{r}$ \\
\hline 0.53 & $4.20 \mathrm{k}$ & $3.20 \mathrm{~m}$ & $3.00 \mathrm{n}$ & $3.00 \mathrm{n}$ \\
\hline 0.65 & $5.40 \mathrm{~g}$ & $5.10 \mathrm{~h}$ & $5.00 \mathrm{i}$ & $4.90 \mathrm{j}$ \\
\hline 0.75 & $7.30 \mathrm{~d}$ & $7.20 \mathrm{e}$ & $7.01 \mathrm{f}$ & $7.00 \mathrm{f}$ \\
\hline 0.85 & $8.40 \mathrm{a}$ & $8.40 \mathrm{a}$ & $8.30 \mathrm{~b}$ & $8.20 c$ \\
\hline \multicolumn{5}{|c|}{ desorption } \\
\hline 0.11 & $2.20 \mathrm{t}$ & $1.49 \mathrm{x}$ & $1.30 \mathrm{y}$ & $1.10 \mathrm{z}$ \\
\hline 0.23 & $2.30 \mathrm{~s}$ & $1.60 \mathrm{w}$ & $1.30 \mathrm{y}$ & $1.30 \mathrm{y}$ \\
\hline 0.32 & $3.00 \mathrm{r}$ & $2.20 \mathrm{t}$ & $2.00 \mathrm{u}$ & $1.90 \mathrm{v}$ \\
\hline 0.44 & $3.80 \mathrm{~m}$ & $3.50 \mathrm{o}$ & $3.10 \mathrm{q}$ & $3.00 \mathrm{r}$ \\
\hline 0.53 & $4.80 \mathrm{k}$ & 4.001 & $3.70 \mathrm{n}$ & $3.40 \mathrm{p}$ \\
\hline 0.65 & $5.90 \mathrm{~g}$ & $5.40 \mathrm{~h}$ & $5.30 \mathrm{i}$ & $5.10 \mathrm{j}$ \\
\hline 0.75 & $7.90 \mathrm{~d}$ & $7.40 \mathrm{e}$ & $7.20 \mathrm{f}$ & $7.20 \mathrm{f}$ \\
\hline 0.85 & $9.20 \mathrm{a}$ & $8.50 \mathrm{~b}$ & $8.40 \mathrm{c}$ & $8.40 \mathrm{c}$ \\
\hline
\end{tabular}

The same letters in each column are not statistically different $(\mathrm{p}<0.05)$.

pistachio powder. Sadeghi et al. (2016) reported that the GAB model was fitted isotherm curve with more accuracy. Muzaffar and Kumar (2016) investigated the moisture sorption isotherms of spray dried tamarind pulp powder. They reported that the GAB model best describes experimental adsorption data through the entire range of water activity. In another study, Maskan and Karatas (1997) studied sorption characteristics of whole pistachio nuts. The results of this review showed that the BET, GAB and Oswin models fitted the isotherm curves with high accuracy.

The predicted values of moisture content against experimental values for Caurie model at storage temperature of $35^{\circ} \mathrm{C}$ are shown in Fig. 2; as seen, there is a high correlation between the two data sets.

The monolayer moisture content $\left(\mathrm{X}_{\mathrm{o}}\right)$ is defined as the minimum moisture content covering hydrophilic sites on the material surface. $X_{o}$ is of notable importance to the

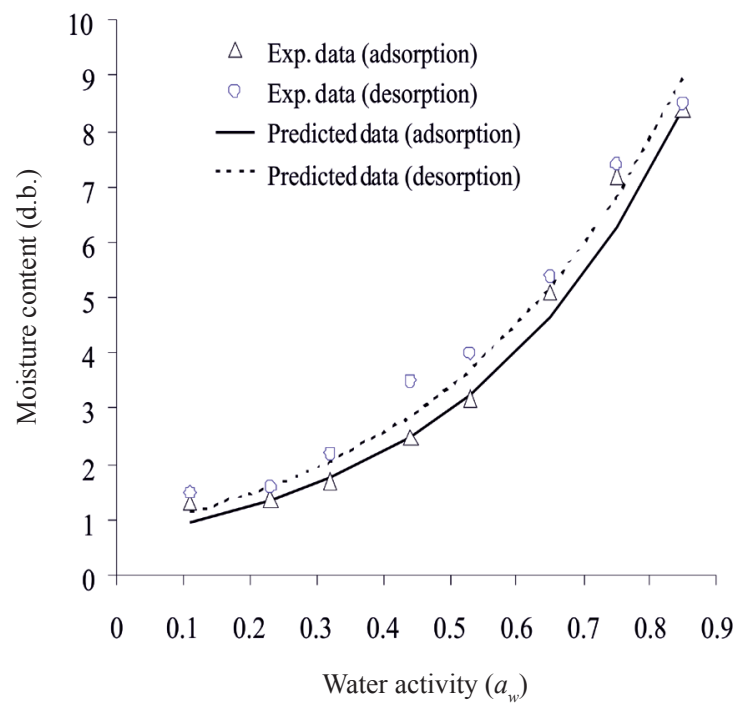

Fig 2. Comparison between the experimental and predicted isotherms of pistachio powder using the Caurie model at temperature of $35^{\circ} \mathrm{C}$.

physicochemical stability of dehydrated materials with regard to lipid oxidation, enzymatic activity, non-enzymatic browning, flavour component preservation and structural characteristics. Arslan and Toğrul (2005) claim that strong hydrophilic bonds appear on polar sites in the food hold water on the monolayer zone.

The values of $\mathrm{X}_{\mathrm{o}}$ of pistachio powder computed by the BET and GAB models at the temperature of 15, 25, 35, and $40^{\circ} \mathrm{C}$ for both isotherms (ie adsorption/desorption) are presented in Table 3. The upshot of this research indicated that the $\mathrm{X}_{\mathrm{o}}$ of pistachio powder at different temperatures for both the adsorption and desorption isotherms for the two models, BET and GAB, ranged between 1.514-1.595 $\mathrm{g} \mathrm{g}^{-1}$ dry basis and 1.404-2.585 $\mathrm{g} \mathrm{g} \mathrm{g}^{-1}$ dry basis, respectively. These results show agreement with the results of Polatoğlu et al. (2011).

Hysteresis is an important factor during the storage and packaging of food. Most drying materials display 'hysteresis' in that the two isotherms (ie adsorption and desorption) are not identical. Therefore, determining the area between adsorption and desorption isotherm curves the hysteresis can be calculated (Fig. 3). As we know, one of the important applications of the definite integration method is the calculation of the area enclosed between the two curves.

So by using this method and the area enclosed between the adsorption and desorption isotherm curves (Fig. 3), hysteresis value can be calculated numerically as shown below:

$$
\mathrm{S}=\left|\int_{a_{w, 1}}^{a_{w, 2}}\left(f\left(a_{w}\right)-g\left(a_{w}\right)\right) d a_{w}\right|
$$


T a b l e 3. Coefficients of the models and statistical parameters for experimental adsorption/desorption data at different temperatures

\begin{tabular}{|c|c|c|c|c|c|c|c|c|c|}
\hline \multirow{3}{*}{ Model } & \multirow{3}{*}{ Constant } & & & \multicolumn{4}{|c|}{ Temperature $\left({ }^{\circ} \mathrm{C}\right)$} & & \\
\hline & & \multicolumn{2}{|c|}{15} & \multicolumn{2}{|c|}{20} & \multicolumn{2}{|c|}{35} & \multicolumn{2}{|c|}{40} \\
\hline & & adsorption & desorption & adsorption & desorption & adsorption & desorption & adsorption & desorption \\
\hline \multirow{4}{*}{ BET } & $X_{0}$ & 1.549 & 1.549 & 1.538 & 1.595 & 1.514 & 1.581 & 1.519 & 1.571 \\
\hline & $\mathrm{C}$ & -15.15 & -15.15 & 14.38 & -93.58 & 9.799 & 24.60 & 7.018 & 15.44 \\
\hline & MRE & 25.07 & 24.61 & 13.16 & 15.93 & 12.66 & 16.13 & 14.82 & 14.33 \\
\hline & $\mathrm{R}^{2}$ & 0.878 & 0.878 & 0.857 & 0.849 & 0.846 & 0.833 & 0.812 & 0.843 \\
\hline \multirow{5}{*}{ GAB } & $X_{o}$ & 1.970 & 2.585 & 1.552 & 2.279 & 1.441 & 2.049 & 1.404 & 1.986 \\
\hline & $\mathrm{C}$ & 10.47 & 16.84 & 11.50 & 7.787 & 10.42 & 6.414 & 7.991 & 5.802 \\
\hline & $\mathrm{K}$ & 1.823 & 0.880 & 1.011 & 0.910 & 1.024 & 0.944 & 1.032 & 0.950 \\
\hline & MRE & 9.113 & 7.427 & 13.58 & 11.76 & 13.34 & 13.66 & 15.81 & 13.59 \\
\hline & $\mathrm{R}^{2}$ & 0.823 & 0.861 & 0.753 & 0.599 & 0.756 & 0.550 & 0.729 & 0.665 \\
\hline \multirow{4}{*}{$\begin{array}{l}\text { Iglesias } \\
\text { and } \\
\text { Chirife }\end{array}$} & A & 2.345 & 2.689 & 1.523 & 2.055 & 1.363 & 1.777 & 1.261 & 1.621 \\
\hline & B & 1.233 & 1.319 & 1.396 & 1.324 & 1.402 & 1.356 & 1.411 & 1.382 \\
\hline & MRE & 16.50 & 16.02 & 19.69 & 24.14 & 20.51 & 25.94 & 23.63 & 25.68 \\
\hline & $\mathrm{R}^{2}$ & 0.899 & 0.903 & 0.906 & 0.884 & 0.910 & 0.890 & 0.904 & 0.899 \\
\hline \multirow{4}{*}{ Freundlich } & A & 7.464 & 8.289 & 7.283 & 8.020 & 7.207 & 7.897 & 7.259 & 7.933 \\
\hline & B & 1.347 & 1.366 & 1.030 & 1.096 & 0.9719 & 1.007 & 0.9155 & 0.952 \\
\hline & MRE & 18.71 & 16.70 & 26.31 & 18.12 & 26.46 & 20.92 & 27.35 & 19.61 \\
\hline & $\mathrm{R}^{2}$ & 0.837 & 0.865 & 0.831 & 0.888 & 0.846 & 0.879 & 0.853 & 0.906 \\
\hline \multirow{4}{*}{ Halsey } & $\mathrm{K}$ & 5.245 & 6.749 & 2.454 & 3.360 & 2.154 & 2.630 & 1.916 & 2.380 \\
\hline & $\mathrm{n}$ & 1.532 & 1.585 & 1.166 & 1.278 & 1.112 & 1.165 & 1.050 & 1.125 \\
\hline & MRE & 8.778 & 7.181 & 11.30 & 11.93 & 10.52 & 13.57 & 12.47 & 11.25 \\
\hline & $\mathrm{R}^{2}$ & 0.9674 & 0.974 & 0.9655 & 0.958 & 0.9694 & 0.953 & 0.9668 & 0.966 \\
\hline \multirow{4}{*}{ Caurie } & A & 0.311 & 0.452 & -0.239 & 0.028 & -0.373 & -0.173 & -0.506 & -0.285 \\
\hline & B & 2.134 & 2.078 & 2.797 & 2.553 & 2.945 & 2.787 & 3.117 & 2.921 \\
\hline & MRE & 5.599 & 4.420 & 8.874 & 6.575 & 8.946 & 7.612 & 8.625 & 6.065 \\
\hline & $\mathrm{R}^{2}$ & 0.978 & 0.987 & 0.977 & 0.983 & 0.980 & 0.980 & 0.982 & 0.990 \\
\hline
\end{tabular}


According to the presented theories for the determination of hysteresis, the first step is to define the functions $y_{\text {des }}$ $=f\left(a_{w}\right)$ and $y_{a d s}=g\left(a_{w}\right)$. For this purpose, the well known models proposed by various authors can be used for fitting the isotherm curves. In the first stage, the best model describing sorption isotherms was determined by the regression methods and statistical parameters ( $\left.\mathrm{R}^{2}, \mathrm{MRE}\right)$, then the adsorption and desorption functions were defined at various temperatures, and the hysteresis value was obtained from Eq. (3). In this study, the Caurie model was selected as the best model for the description of the adsorption and desorption isotherm curves of pistachio powder. Thus, with regard to coefficients $\mathrm{A}$ and $\mathrm{B}$ at each temperature for both adsorption and desorption (Table 3), hysteresis value can be computed as follows:

$$
\mathrm{S}=\left|\int_{a_{w, 1}}^{a_{w, 2}}\left(\mathrm{e}^{\mathrm{A}} \mathrm{e}^{\mathrm{B} a_{w}}\right) d a_{w}\right|-\left|\int_{a_{w, 1}}^{a_{w, 2}}\left(\mathrm{e}^{\mathrm{A}^{\prime}} \mathrm{e}^{\mathrm{B} a_{w}}\right) d a_{w}\right| .
$$

By substitution of the constant coefficients A, A', B and $\mathrm{B}^{\prime}$ and application of the integration interval, the hysteresis loop area in any temperature could be determined.

Figure 3 shows the general shape of the typical sorption isotherms. They are characterised by three distinct zones, $\mathrm{a}, \mathrm{b}$ and $\mathrm{c}$, which are indicative of monolayer $\left(a_{w}<0.2\right)$, multilayer $\left(0.2 \leq a_{w} \leq 0.6\right)$ and free water $\left(a_{w}>0.6\right)$. Hysteresis loop area for pistachio powder, calculated individually in each zone, and the results are presented in Table 4. The ANOVA results show that the different zones and storage temperatures had meaningful and significant differences $(p<0.05)$ in hysteresis value. When the storage temperature of the

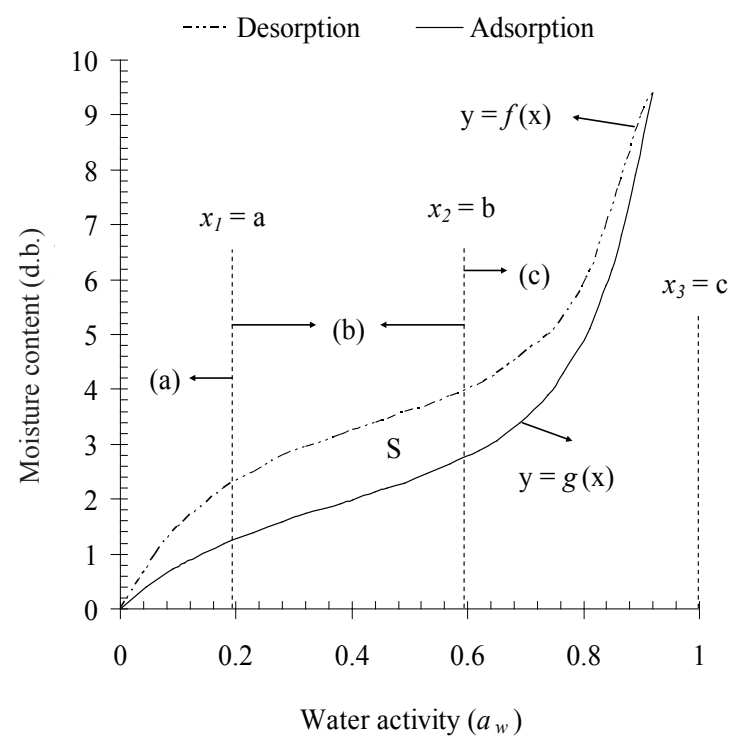

Fig 3. Adsorption and desorption isotherm curves and differences in their regions: (a) monolayer water $(0-0.2)$, (b) multilayer water (0.2-0.6), and (c) free water (0.6-1).
T a b l e 4. Hysteresis distribution in isotherm curve and mean comparison (interaction effects of hysteresis zone and storage temperature) for pistachio powder at different temperatures

\begin{tabular}{|c|c|c|c|c|}
\hline \multirow{2}{*}{$a_{w}$ region } & \multicolumn{4}{|c|}{ Temperature $\left({ }^{\circ} \mathrm{C}\right)$} \\
\hline & 15 & 25 & 35 & 40 \\
\hline \multicolumn{5}{|c|}{ Monolayer } \\
\hline$[0.11,0.20]$ & $2.42 \mathrm{i}$ & $2.81 \mathrm{~h}$ & $1.87 \mathrm{j}$ & $1.85 \mathrm{j}$ \\
\hline \multicolumn{5}{|c|}{ Multilayer } \\
\hline$[0.20,0.60]$ & $16.40 \mathrm{c}$ & $17.72 \mathrm{a}$ & $13.23 \mathrm{e}$ & $12.91 \mathrm{f}$ \\
\hline \multicolumn{5}{|c|}{ Free water } \\
\hline$[0.60,0.85]$ & $17.04 b$ & $13.83 \mathrm{~d}$ & $12.89 \mathrm{f}$ & $11.66 \mathrm{~g}$ \\
\hline \multicolumn{5}{|c|}{ Total } \\
\hline$[0.11,0.85]$ & 35.87 & 34.36 & 28.00 & 26.43 \\
\hline
\end{tabular}

The same letters in each column are not statistically different $(\mathrm{p}<0.05)$.

T a b l e 5. Composition of pistachio nuts

\begin{tabular}{lc}
\hline Chemical composition & $(\%)$ \\
\hline Proteins & $15-21.2$ \\
Fats & $55.2-60.5$ \\
Carbohydrates & $14.9-17.7$ \\
Fibers & $1.7-2$ \\
Ash (minerals) & $2.2-2.5$ \\
\hline
\end{tabular}

pistachio powder increased, its total hysteresis loop area decreased (Table 4). The mean comparison of hysteresis in the different zones (monolayer, multilayer and free water) revealed that the highest hysteresis value was related to multilayer zone $\left(0.2 \leq a_{w} \leq 0.6\right)$ and the storage temperature of $25^{\circ} \mathrm{C}$, which correspond to the capillary condensation region, and this phenomenon decreases with increasing temperature (Tavakolipour and Kalbasi Ashtari, 2008).

Percentage chemical composition of Persian pistachio nuts (Tavakolipour, 2015) is reported in Table 5. As shown, the pistachio nuts have high amounts of protein, so hysteresis starts at high water activities and it extends over the isotherms when $a_{w}$ reaches to zero $\left(a_{w}=0\right)$. As well, in high sugar and pectin foods this phenomenon is pronounced whenever the moisture content becomes lower. In starchy foods, a large loop area is reported with a maximum water activity value of 0.7 (Vega Mercado and Barbosa Canovas, 1996). Generally, knowledge of the amount of hysteresis provides useful information about pistachio powder for the purpose of its being kept in optimal conditions and selected 
suitable packaging materials for water diffusion through packaging layer toward pistachio powder and to extend the shelf life of pistachio powder.

\section{CONCLUSIONS}

1. The sorption data were in good agreement with well known sorption models like the Caurie and Halsey equations. However, the Caurie model was found to be the best to describe the sorption isotherm at all the temperatures studied for pistachio powder.

2. The hysteresis value was determined using the best-fit model and definite integration method for the equilibrium of adsorption and desorption curves. The results indicated that the maximum hysteresis is related to the multi-layer water (in the range of water activity $0.2-0.6$ ), which corresponds to the capillary condensation region, and this phenomenon decreases with increasing temperature.

\section{REFERENCES}

AOAC, 1990. Official Methods of Analysis of the Association of Official Analytical Chemists, Association of Official Analytical Chemists, Washington, DC, USA.

Arena E., Ballistreri G., and Fallico B., 2013. Effect of postharvest storage temperatures on the quality parameters of pistachio nuts. Czech J. Food Sci., 31, 467-473.

Arslan N. and Toğrul H., 2005. Modelling of water sorption isotherms of macaroni stored in a chamber under controlled humidity and thermodynamic approach. J. Food Eng., 69, 133-145.

Ayrancy E. and Dalgic C., 1992. Moisture sorption isotherms of Pistacia terebinthus L. and its protein isolate. Lebensm.Wiss.u. Technol., 25, 482-483.

Biquet B. and Labuza T.P., 1988. Evaluation of the moisture permeability characteristics of chocolate fills as an edible moisture barrier. J. Food Sci., 53, 989-997.

Brunauer S., Emmett P.H., and Teller E., 1938. Adsorption of gases in multimolecular layers. J. Am. Chem. Soc., 60, 309-319.

FAO, 2012. Food and Agricultural Organization of the United Nations, FAOSTAT online-statistical service (FAO Rome). $<$ http://apps.fao.org $>$

Labuza T.P., 1984. Moisture sorption: practical aspects of isotherm measurement and use. St. Paul, MN: American Association of Cereal Chemists.

Majd K.M., Karparvarfard S.H., Farahnaky A., and Ansari S., 2014. Thermodynamic properties of water sorption isotherms of grape seed. Int. Agrophys., 28, 63-71.

Maskan M. and Karatag S., 1997. Sorption characteristics of whole pistachio nuts (Pistacia vera L.). Drying Technol., 15(3-4), 1119-1139.

Mokhtarian M., Heydari Majd M., Koushki F., Bakhshabadi H., Daraei Garmakhany A., and Rashidzadeh S., 2014. Optimisation of pumpkin mass transfer kinetic during osmotic dehydration using artificial neural network and response surface methodology modelling. Quality Assur. Safety Crops Food., 6(2), 201-214.

Moreira R., Chenlo F., and Torres M.D., 2009. Simplified algo- rithm for the prediction of water sorption isotherms of fruits, vegetables and legumes based upon chemical composition. J. Food Eng., 94, 334-343.

Mrad N.D., Bonazzi C., Courtois F., Kechaou N., and Mihoubi N.B., 2013. Moisture desorption isotherms and glass transition temperatures of osmo-dehydrated apple and pear. Food Bioproduct Process., 91(2), 121-128.

Muzaffar K. and Kumar P., 2016. Moisture sorption isotherms and storage study of spray dried tamarind pulp powder. Powder Technol., doi: 10.1016/j.powtec.2015.12.046.

Noshad M., Mohebbi M., Shahidi F., and Mortazavi S.A., 2012. Effect of osmosis and ultra-sound pretreatment on the moisture adsorption isotherms of quince. J. Food Bioprod. Proc., 90, 266-274.

Ocieczek A., 2012. Sorption properties of various types of commercial wheat flour. Acta Agrophys., 19(2), 365-377.

Ocieczek A., 2014. Comparison of the sorption properties of milk powder with lactose and without lactose. Acta Agrophys., 21(4), 457-468.

Polatoğlu B., Bese A.V., Kaya M., and Aktas N., 2011. Moisture adsorption isotherms and thermodynamics properties of sucuk (Turkish dry-fermented sausage). Food Bioproduc. Process., 89(4), 449-456.

Sadeghi M., Mehryar E., Razavi J., and Mireei S.A., 2016. Moisture sorption isotherm and glass transition temperature of date powder in terms of various model systems. J. Food Proc. Eng., 39, 61-68.

Sahin S. and Sumnu S.G., 2006. Physical properties of foods. Springer, New York.

Saitta M., Giuffrida D., Torre G.L.L., Potortì A.G., and Dugo G., 2009. Characterisation of alkylphenols in pistachio (Pistacia vera L.) kernels. Food Chem., 117, 451-455.

Shivhare U.S., Arora S., Ahmed J., and Raghavan G.S.V., 2004. Moisture adsorption iso-therms for mushroom. Lebensm.Wiss.u. Technol., 37, 133-137.

Singh R.R.B., Rao K.H., Anjaneyulu A.S.R., and Patil G.R., 2001. Moisture sorption properties of smoked chicken sausages from spent hen meat. Food Res. Int., 34, 143-148.

Staudt P.B., Kechinski C.P., Tessaro I.C., Marczak L.D.F., Soares R.D.E.P., and Cardozo N.S.M., 2013. A new method for predicting sorption isotherms at different temperatures using the BET model. J. Food Eng., 114, 139-145.

Tavakolipour H., 2015. Postharvest operations of pistachio nuts. J. Food Sci. Technol., 52(2), 1124-1130.

Tavakolipour H. and Kalbasi Ashtari A., 2008. Estimation of moisture sorption isotherms in Kerman pistachio nuts. J. Food Process Eng., 31, 564-582.

Tavakolipour H. and Mokhtarian M., 2012. Neural network approaches for prediction of pistachio drying kinetics. Int. J. Food Eng., 8, 3-42.

Vega Mercado H. and Barbosa Canovas V., 1996. Dehydration of Foods. Chapman and Hall, New York.

Zomorodian A.A. and Tavakoli R.A., 2007. The adsorptiondesorption hysteresis effect on pistachio nuts. J. Agric. Sci. Technol., 9, 259-265.

Zomorodian A., Kavoosi Z., and Momenzadeh L., 2011. Determination of EMC isotherms and appropriate mathematical models for canola. J. Food Bioprod. Proc., 89, 407-413. 